\title{
Body donation for research and teaching purposes: the contribution of blood donation units in the progress of anatomical science
}

\author{
A. Kostorrizos ${ }^{1}$, A. Koukakis ${ }^{1}$, A. Samolis ${ }^{1}$, V. Protogerou ${ }^{1}$, T. Mariolis-Sapsakos ${ }^{2}$, \\ M. Piagkou' ${ }^{1}$ K. Natsis ${ }^{3}$, G.P. Skandalakis ${ }^{1}$, T. Troupis ${ }^{1}$ \\ ${ }^{1}$ Department of Anatomy, School of Medicine, Faculty of Health Sciences, \\ National and Kapodistrian University of Athens, Greece \\ ${ }^{2}$ Anatomy and Histology Laboratory, School of Nursing, Faculty of Health Sciences, \\ National and Kapodistrian University of Athens, Greece \\ ${ }^{3}$ Department of Anatomy and Surgical Anatomy, Faculty of Health Sciences, School of Medicine, \\ Aristotle University of Thessaloniki, Greece
}

[Received: 24 September 2018; Accepted: 10 October 2018]

Background: Cadaver's dissection has a fundamental role in teaching and understanding the anatomy. Postmortem body donation (PMBD) is an important source of cadavers and provides an opportunity to carry out research or educational activities in medicine and surgery. The objective of the current study is to determine the perspectives and attitudes toward PMBD among blood donors (BLD) and elderly people. These data are fundamental to highlight the PMBD extent and individual factors that might influence PMBD.

Materials and methods: Six hundred and fifty questionnaires were distributed to 500 (327 male and 173 female, mean age $39.9 \pm 9.6$ years) blood donors (BLD) and 150 elderly people (62 males and 88 females, mean age $74 \pm 9.4$ years). A specially designed self-administered questionnaire covering demographic data, knowledge and attitude of the participants concerning body donation (BD) was used. Results: Concerning the perception of BD among BLD and elderly people, the most common reason for $B D$ in both study groups was the contribution in research, while the commonest reason for hesitating about $B D$ was the lack of information, following by personal reasons. The $B L D$ were more likely to be interested in $B D$ for contribution in research and personal reasons. Additionally, BLD were less likely than the elderly to hesitate about $B D$ for religious and personal reasons and more likely to hesitate about $B D$ for not being informed. BLD who were interested in $B D$ for contribution in research were significantly older. Elderly people who hesitated about $B D$ for personal reasons were significantly older. In the BLD group, those who responded that blood and body donation are the same were significantly younger, while in the elderly group - significantly older. The proportion of BLD who declared that blood and body donation is the same was significantly higher in more educated people. Conclusions: A need for well-organised and informative BD programmes is evident. Orientating the public towards this practice is of high moral and medical value, since with this important promotion the altruistic act of $B D$ will expand globally. (Folia Morphol 2019; 78, 3: 575-581)

Key words: body donation, anatomy, teaching, medical education, cadaver

Address for correspondence: T.G. Troupis, MD, PhD, Department of Anatomy, School of Medicine, Faculty of Health Sciences, National and Kapodistrian University of Athens, 75 Mikras Asias str., Goudi, 11527 Athens, Greece, tel: +30-210-7462388, fax: +30-210-7462398, e-mail: ttroupis@gmail.com; ttroupis@med.uoa.gr 


\section{INTRODUCTION}

"The dead teach the living" is the motto reflecting the fundamental role of cadavers' dissection in teaching and understanding the anatomy, surgical practice and novel scientific techniques [3, 4, 17, 22]. Postmortem body donation (PMBD) is an important source of cadavers and provides an opportunity to carry out research or educational activities in medicine and surgery. PMBD is defined as the informed and free act of donating whole body after death for medical education and research. This altruistic choice is of high moral value [5]. Culture, society and spirituality contribute to the variable characteristics of body donors and body donation (BD) programmes worldwide. PMBD is still relatively rare, and in attempts to increase $B D$, many countries have instituted programmes and regulations surrounding the donation of cadavers or body parts. BD programmes represent the main source of cadavers for the Departments of Anatomy. Cadavers' dissection provides a unique opportunity to integrate anatomical and clinical education. Traditional dissection courses $[8,9,21]$ have been an integral part of medical education since the 1800 s $[13,20]$. Although the development of medical technologies, cadavers' dissection remains the highlight of anatomy education, as it provides students a clear aspect of the anatomical structures and their spatial orientation within the body, as well as the understanding of anatomical variation within the same or different populations [17, 18, 20]. Research has shown that body donors for the science of anatomy are a unique and irreplaceable learning tool for undergraduate medical education [18]. Previous studies focused on cadaveric donations, emphasizing on individual donations, on gender differences to explain the different context of voluntary donations $[7,14]$. They concluded that the $\mathrm{BD}$ is incited by the altruism which differs by gender, age and socioeconomic and educational status of the population. A tendency for BD was highlighted for married couples, as they donated together [14].

The objective of the current study is to determine the perspectives and attitudes toward PMBD among blood donors and elderly people. These data are fundamental to highlight the PMBD extent and individual factors that might influence PMBD.

\section{MATERIALS AND METHODS}

The current study was conducted in the Blood donation Unit of Sotiria Regional Chest Diseases Hospital (Athens region) and in the Elderly Care Unit of Agion
Table 1. Demographic characteristics of the sample (600 subjects, 500 blood donors and 150 elderly)

\begin{tabular}{lcc}
\hline & $\begin{array}{c}\text { Blood donors } \\
\text { (n = 500) }\end{array}$ & $\begin{array}{c}\text { Elderly } \\
\text { (n = 150) }\end{array}$ \\
\hline Gender: & & \\
Males & $327(65.4 \%)$ & $62(41.3 \%)$ \\
Females & $173(34.6 \%)$ & $88(58.7 \%)$ \\
Men age \pm SD & $39.9 \pm 9.6$ & $74.0 \pm 9.4$ \\
Mean BMl \pm SD & $25.7 \pm 3.6$ & $29.1 \pm 4.9$ \\
BMl: & & \\
Normal & $210(42.0 \%)$ & $24(16.0 \%)$ \\
Overweight & $239(47.8 \%)$ & $66(44.0 \%)$ \\
Obese & $51(10.2 \%)$ & $60(40.0 \%)$ \\
Educational level: & & \\
None/primary school & $1(0.2 \%)$ & $78(52.0 \%)$ \\
Middle school & $3(0.6 \%)$ & $38(25.3 \%)$ \\
High school & $162(32.4 \%)$ & $33(22.0 \%)$ \\
TEl & $149(29.8 \%)$ & $0(0.0 \%)$ \\
University/postgraduate studies & $185(37 \%)$ & $0(0.0 \%)$ \\
Other & $0(0.0 \%)$ & $1(0.7 \%)$ \\
Religion: & & \\
Christian Orthodox & & \\
Other & & \\
Family history & $375(95.0 \%)$ & $149(99.3 \%)$ \\
Personal history & $25(5.0 \%)$ & $1(0.7 \%)$ \\
Previous surgery & $81(16.2 \%)$ & $26(17.3 \%)$ \\
Smoking & $7(1.4 \%)$ & $93(62.0 \%)$ \\
Alcohol consumption & $52(10.4 \%)$ & $43(28.7 \%)$ \\
Having tattoo & $163(32.6 \%)$ & $25(16.7 \%)$ \\
\hline & $35(7.0 \%)$ & $10(6.7 \%)$ \\
\hline & $33(6.6 \%)$ & $1(0.7 \%)$ \\
\hline
\end{tabular}

$\mathrm{BMI}$ — body mass index; SD — standard deviation; TEI — Technological Educational Institute

Anargyron after obtaining a signed informed permission from the Ethical Committees of the Institutions.

Six hundred and fifty questionnaires were distributed to 500 (327 male and 173 female, mean age $39.9 \pm 9.6$ years) blood donors (BLD) and 150 elderly people (62 males and 88 females, mean age $74 \pm 9.4$ years). Samples' characteristics are summarised in Table 1. All participants were of Greek nationality (Caucasian whites).

A specially designed self-administered questionnaire covering demographic data, knowledge and attitude of the participants concerning BD was prepared and given for response. The methodology was explained to all participants and clarifications were provided without influencing the respondents. The inclusion criterion for the participation in the study was the age of 18 years and above and exclusion criterion was the denial of consent. Respondents were assured that their anonymity would be respected. The process of collection of the completed 
Table 2. Perceptions of blood donors and elderly concerning body donation

\begin{tabular}{lccc}
\hline & $\begin{array}{c}\text { Blood donors } \\
(\mathbf{n}=\mathbf{5 0 0})\end{array}$ & $\begin{array}{c}\text { Elderly } \\
(\mathbf{n}=150)\end{array}$ & P* \\
\hline $\begin{array}{l}\text { Interested in being body } \\
\text { donor for: }\end{array}$ & & & \\
$\begin{array}{l}\text { Contributing in research } \\
\text { (physicians' education) }\end{array}$ & $265(53.0 \%)$ & $39(26.0 \%)$ & $<0.001$ \\
Personal reasons & $107(21.4 \%)$ & $16(10.7 \%)$ & 0.003 \\
Financial reasons & $4(0.8 \%)$ & $2(1.3 \%)$ & $0.626^{* *}$ \\
Hesitating in being body & & & \\
donor for: & & & \\
Religious reasons & $31(6.2 \%)$ & $31(20.7 \%)$ & $<0.001$ \\
Personal reasons & $105(21 \%)$ & $65(43.3 \%)$ & $<0.001$ \\
Not being informed & $167(33.4 \%)$ & $25(16.7 \%)$ & $<0.001$ \\
Not being appropriate for it & $9(1.8 \%)$ & $38(25.3 \%)$ & $<0.001$ \\
Is blood and body dona- & $51(10.2 \%)$ & $19(12.7 \%)$ & 0.393 \\
tion the same? & & & \\
If no, why: & & & \\
It is unknown & $129(28.7 \%)$ & $17(13 \%)$ & $<0.001$ \\
It scares me & $65(14.5 \%)$ & $34(26 \%)$ & 0.002 \\
Religious reasons & $27(6.0 \%)$ & $13(9.9 \%)$ & 0.120 \\
Personal/Family reasons & $103(22.9 \%)$ & $84(64.1 \%)$ & $<0.001$ \\
Simple procedure & $130(29.0 \%)$ & $89(67.9 \%)$ & $<0.001$ \\
$\begin{array}{l}\text { Possible reaction from } \\
\text { friends and family }\end{array}$ & $107(23.8 \%)$ & $8(6.1 \%)$ & $<0.001$ \\
Not being informed & $116(25.8 \%)$ & $27(20.6 \%)$ & 0.222 \\
\hline & & &
\end{tabular}

*Pearson's chi-square test; ${ }^{* *}$ Fisher's exact test

questionnaires as well as the validation of the answered fields was supervised by an academic teacher in collaboration with post-graduate medical students. Responses from all questionnaires were registered in a database using 2010 Microsoft Excel for Windows. Records included each registrant's full name, year of birth, date of registration, gender, race/ethnicity, religious affiliation, marital status, and primary (current or past) occupation.

\section{Statistical analysis}

Continuous variables are presented with mean \pm standard deviation (SD). Quantitative variables are presented with absolute and relative frequencies. For the comparison of proportions, $\chi^{2}$ and Fisher's exact tests were used. For the comparison of means between two groups, the Student's t-test was computed. All $p$ values reported are two-tailed. Analysis was conducted using SPSS statistical software (version 22.0) for Windows. Statistical differences among groups were studied using a one-way ANOVA analysis and a post hoc Bonferroni test. Significance level was set at $p<0.05$.

\section{RESULTS}

The majority of participants were Christian Orthodox (95\% in BLD group and $99.3 \%$ in the elderly group). Family history existed in $16.2 \%$ of the BLD group and in $17.3 \%$ of the elderly group, while personal history was present at $1.4 \%$ in the BLD group and at $62.0 \%$ in the elderly group. A percentage of $10.4 \%$ and $28.7 \%$ of the BLD and the elderly, respectively, had a previous surgery. The proportion of smokers was $32.6 \%$ in BLD and $16.7 \%$ in the elderly. Concerning BD perception among BLD and elderly people (Table 2), the most common reason for BD was the contribution in research in both study groups (Figs. 1, 2). The most common reason for hesitating about BD (Fig. 3) was the lack of information following by personal reasons in the BLD group and personal reasons in the elderly group (Fig. 4). The percentage of positive responders in the question: "Is blood and body donation the same?" was $10.2 \%$ in BLD and $12.7 \%$ in the elderly group. Comparing the perceptions between two groups, BLD were more likely to be interested in $\mathrm{BD}$ for contribution in research and personal reasons. Additionally, BLD were less likely than elderly patients to have hesitation in being body donor for religious or personal reasons and more likely to have hesitation in being body donor for not being informed. Comparing the responses for the reason that blood and $\mathrm{BD}$ are not the same, BLD were less likely than the elderly, to have marked "It scares me", personal/family reasons and simple procedure and more likely to mark "It is unknown" and "Possible reaction from friends and family". Tables 3 and 4 summarise the gender and age differences in perceptions of BLD and elderly people concerning BD. Regarding to the responses for the reason that blood and $B D$ are not the same, female BLD were more likely than the male ones to mark "It scares me", while in the elderly group, males were more likely to be interested in being body donors for contribution in research. BLD who declared their interest in being BD for contribution in research were significantly older. Also, BLD who hesitated about BD for "Not being informed" or those who responded "It is unknown", "Possible reaction from friends and family" and "Not being informed" for the explanation why blood and BD are not the same were significantly younger. Elderly people who hesitated about $\mathrm{BD}$ for personal reasons were significantly older. In the BLD group, those who responded that blood and $\mathrm{BD}$ are the same were significantly younger, while in the elderly group - significantly older. The proportion of BLD who declared that blood donation and BD are the same was significantly higher in more educated people 


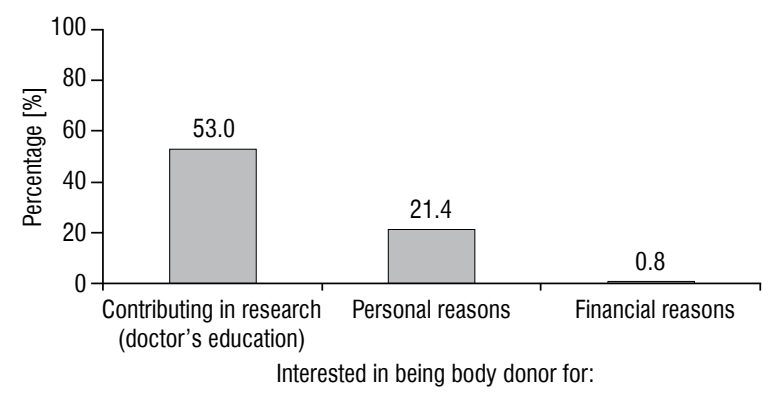

Figure 1. Reasons for blood donors being interested in body donation.

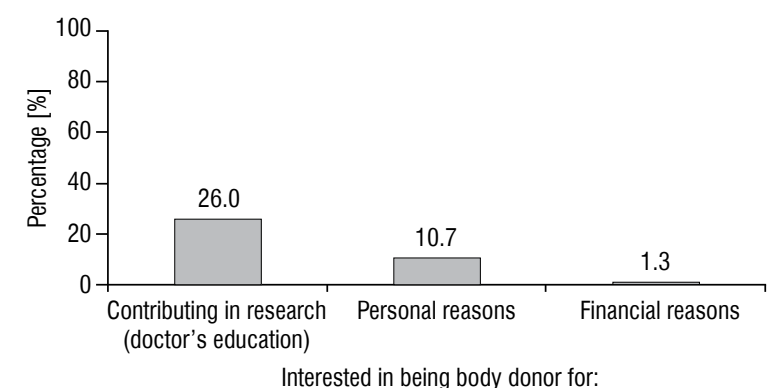

Figure 2. Reasons for elderly people being interested in body donation.

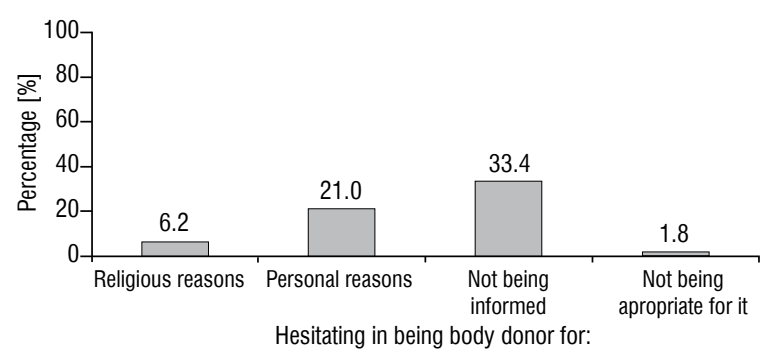

Figure 3. Reasons for blood donors hesitating about body donation.

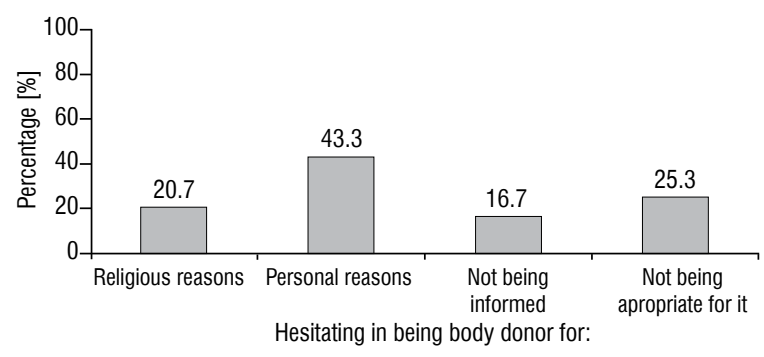

Figure 4. Reasons for elderly people hesitating about body donation.

$(p=0.050)$. Also, BLD not being Christian Orthodox were more likely to respond "Personal/family reasons" $(p=0.006)$ and "Simple procedure" $(p=0.009)$ for the explanation why blood and $\mathrm{BD}$ are not the same
Table 3. Age differences in perceptions of blood donors and elderly people concerning body donation - mean (SD)

\begin{tabular}{|c|c|c|c|c|c|}
\hline & & $\begin{array}{c}\text { Blood } \\
\text { donors } \\
(n=500)\end{array}$ & $\mathbf{P}^{*}$ & $\begin{array}{c}\text { Elderly } \\
(n=150)\end{array}$ & $\mathbf{P}^{*}$ \\
\hline \multicolumn{6}{|c|}{ Interested in being body donor for: } \\
\hline \multirow{2}{*}{$\begin{array}{l}\text { Contributing in } \\
\text { research (doc- } \\
\text { tors' education) }\end{array}$} & No & $37.9(9.5)$ & $<0.001$ & $74.0(8.8)$ & 0.914 \\
\hline & Yes & $41.6(9.4)$ & & $74.2(10.9)$ & \\
\hline \multirow{2}{*}{$\begin{array}{l}\text { Personal } \\
\text { reasons }\end{array}$} & No & $39.9(9.7)$ & 0.822 & $74.1(9.2)$ & 0.808 \\
\hline & Yes & $39.7(9.0)$ & & $73.5(10.9)$ & \\
\hline \multirow{2}{*}{$\begin{array}{l}\text { Financial } \\
\text { reasons }\end{array}$} & No & $39.9(9.6)$ & 0.737 & $74.1(9.4)$ & 0.875 \\
\hline & Yes & $38.3(3.0)$ & & $73.0(1.4)$ & \\
\hline \multicolumn{6}{|c|}{ Hesitating in being body donor for: } \\
\hline \multirow{2}{*}{$\begin{array}{l}\text { Religious } \\
\text { reasons }\end{array}$} & No & $39.9(9.7)$ & 0.480 & $74.0(9.6)$ & 0.996 \\
\hline & Yes & $38.7(8.4)$ & & $74.0(8.4)$ & \\
\hline \multirow{2}{*}{$\begin{array}{l}\text { Personal } \\
\text { reasons }\end{array}$} & No & $40.2(9.6)$ & 0.116 & $72.5(9.1)$ & 0.024 \\
\hline & Yes & $38.6(9.4)$ & & $76.0(9.4)$ & \\
\hline \multirow{2}{*}{$\begin{array}{l}\text { Not being } \\
\text { informed }\end{array}$} & No & $40.8(9.0)$ & 0.001 & $73.6(9.3)$ & 0.168 \\
\hline & Yes & $37.9(10.4)$ & & $76.4(9.4)$ & \\
\hline \multirow{2}{*}{$\begin{array}{l}\text { Not being } \\
\text { appropriate for it }\end{array}$} & No & $39.9(9.6)$ & 0.535 & $74.0(9.0)$ & 0.897 \\
\hline & Yes & $37.9(9.0)$ & & $74.2(10.4)$ & \\
\hline \multirow{2}{*}{$\begin{array}{l}\text { Is blood and } \\
\text { body donation } \\
\text { the same? }\end{array}$} & No & $40.2(9.5)$ & 0.025 & $73.4(9.4)$ & 0.025 \\
\hline & Yes & $37.0(9.6)$ & & $78.5(8.1)$ & \\
\hline \multicolumn{6}{|l|}{ If no, why: } \\
\hline \multirow[t]{2}{*}{ It is unknown } & No & $40.8(9.1)$ & 0.023 & $73.8(9.4)$ & 0.207 \\
\hline & Yes & $38.6(10.3)$ & & $70.7(8.8)$ & \\
\hline \multirow[t]{2}{*}{ It scares me } & No & $40.4(9.6)$ & 0.239 & $73.8(9.3)$ & 0.360 \\
\hline & Yes & $38.9(9.4)$ & & $72.1(9.6)$ & \\
\hline \multirow{2}{*}{$\begin{array}{l}\text { Religious } \\
\text { reasons }\end{array}$} & No & $40.1(9.6)$ & 0.754 & $73.4(9.5)$ & 0.875 \\
\hline & Yes & 40.7 (8.3) & & $73.0(8.8)$ & \\
\hline \multirow{2}{*}{$\begin{array}{l}\text { Personal/family } \\
\text { reasons }\end{array}$} & No & 40.7 (9.5) & 0.055 & $71.6(8.6)$ & 0.106 \\
\hline & Yes & $38.6(9.5)$ & & $74.4(9.7)$ & \\
\hline \multirow{2}{*}{$\begin{array}{l}\text { Simple } \\
\text { procedure }\end{array}$} & No & $40.4(9.8)$ & 0.508 & $72.5(9.7)$ & 0.458 \\
\hline & Yes & $39.7(8.9)$ & & $73.8(9.3)$ & \\
\hline \multirow{2}{*}{$\begin{array}{l}\text { Possible } \\
\text { reaction from } \\
\text { friends and } \\
\text { family }\end{array}$} & No & $41.3(9.4)$ & $<0.001$ & 73.2 (9.2) & 0.297 \\
\hline & Yes & $36.5(9.2)$ & & $76.8(12.6)$ & \\
\hline \multirow{2}{*}{$\begin{array}{l}\text { Not being } \\
\text { informed }\end{array}$} & No & $40.7(90)$ & 0.050 & $73.5(9.5)$ & 0.828 \\
\hline & Yes & $38.7(10.7)$ & & $73.0(9.1)$ & \\
\hline
\end{tabular}

*Student's t-test; SD — standard deviation

as compared to the Christian Orthodox people. BLD subjects having a tattoo were more likely to answer that blood donation and BD are the same $(p=0.003)$. BLD with family history $(p=0.002)$ or those with previous 
Table 4. Perceptions of blood donors and elderly people concerning body donation by gender

\begin{tabular}{|c|c|c|c|c|c|c|c|}
\hline & & \multicolumn{3}{|c|}{ Blood donors $(n=500)$} & \multicolumn{3}{|c|}{ Elderly $(n=150)$} \\
\hline & & Males & Females & $\mathbf{P}^{*}$ & Males & Females & $\mathbf{P}^{*}$ \\
\hline \multicolumn{8}{|l|}{ Interested in being body donor for: } \\
\hline \multirow[t]{2}{*}{ Contributing in research (physicians' education) } & No & $144(44.0 \%)$ & $91(52.6 \%)$ & 0.068 & $39(62.9 \%)$ & $72(81.8 \%)$ & 0.009 \\
\hline & Yes & $183(56.0 \%)$ & $82(47.4 \%)$ & & $23(37.1 \%)$ & $16(18.2 \%)$ & \\
\hline \multirow[t]{2}{*}{ Personal reasons } & No & $265(81.0 \%)$ & $128(74.0 \%)$ & 0.067 & $56(90.3 \%)$ & $78(88.6 \%)$ & 0.742 \\
\hline & Yes & $62(19.0 \%)$ & $45(26.0 \%)$ & & $6(9.7 \%)$ & $10(11.4 \%)$ & \\
\hline \multirow[t]{2}{*}{ Financial reasons } & No & $324(99.1 \%)$ & $172(99.4 \%)$ & $1.000^{* *}$ & $61(98.4 \%)$ & $87(98.9 \%)$ & $1.000^{* *}$ \\
\hline & Yes & $3(0.9 \%)$ & $1(0.6 \%)$ & & $1(1.6 \%)$ & $1(1.1 \%)$ & \\
\hline \multicolumn{8}{|l|}{ Hesitating in being body donor for: } \\
\hline \multirow[t]{2}{*}{ Religious reasons } & No & $307(93.9 \%)$ & $162(93.6 \%)$ & 0.915 & $50(80.6 \%)$ & $69(78.4 \%)$ & 0.739 \\
\hline & Yes & $20(6.1 \%)$ & $11(6.4 \%)$ & & $12(19.4 \%)$ & $19(21.6 \%)$ & \\
\hline \multirow[t]{2}{*}{ Personal reasons } & No & $266(81.3 \%)$ & $129(74.6 \%)$ & 0.077 & $34(54.8 \%)$ & $51(58 \%)$ & 0.705 \\
\hline & Yes & $61(18.7 \%)$ & $44(25.4 \%)$ & & $28(45.2 \%)$ & $37(42 \%)$ & \\
\hline \multirow[t]{2}{*}{ Not being informed } & No & $219(67 \%)$ & $114(65.9 \%)$ & 0.808 & $49(79.0 \%)$ & $76(86.4 \%)$ & 0.235 \\
\hline & Yes & $108(33 \%)$ & $59(34.1 \%)$ & & $13(21.0 \%)$ & $12(13.6 \%)$ & \\
\hline \multirow[t]{2}{*}{ Not being appropriate for it } & No & $322(98.5 \%)$ & $169(97.7 \%)$ & $0.504^{* *}$ & $47(75.8 \%)$ & $65(73.9 \%)$ & 0.788 \\
\hline & Yes & $5(1.5 \%)$ & $4(2.3 \%)$ & & $15(24.2 \%)$ & $23(26.1 \%)$ & \\
\hline \multirow[t]{2}{*}{ Is blood and body donation the same? } & No & $291(89.0 \%)$ & $158(91.3 \%)$ & 0.411 & $53(85.5 \%)$ & $78(88.6 \%)$ & 0.568 \\
\hline & Yes & $36(11.0 \%)$ & $15(8.7 \%)$ & & $9(14.5 \%)$ & $10(11.4 \%)$ & \\
\hline \multicolumn{8}{|l|}{ If no, why: } \\
\hline \multirow[t]{2}{*}{ It is unknown } & No & $206(70.8 \%)$ & $114(72.2 \%)$ & 0.761 & $46(86.8 \%)$ & $68(87.2 \%)$ & 0.948 \\
\hline & Yes & $85(29.2 \%)$ & $44(27.8 \%)$ & & $7(13.2 \%)$ & $10(12.8 \%)$ & \\
\hline \multirow[t]{2}{*}{ It scares me } & No & $258(88.7 \%)$ & $126(79.7 \%)$ & 0.010 & $43(81.1 \%)$ & $54(69.2 \%)$ & 0.127 \\
\hline & Yes & $33(11.3 \%)$ & $32(20.3 \%)$ & & $10(18.9 \%)$ & $24(30.8 \%)$ & \\
\hline \multirow[t]{2}{*}{ Religious reasons } & No & $275(94.5 \%)$ & 147 (93.0\%) & 0.533 & $46(86.8 \%)$ & $72(92.3 \%)$ & 0.300 \\
\hline & Yes & $16(5.5 \%)$ & 11 (7.0\%) & & $7(13.2 \%)$ & $6(7.7 \%)$ & \\
\hline \multirow[t]{2}{*}{ Personal/Family reasons } & No & $222(76.3 \%)$ & 124 (78.5\%) & 0.598 & $16(30.2 \%)$ & $31(39.7 \%)$ & 0.263 \\
\hline & Yes & $69(23.7 \%)$ & $34(21.5 \%)$ & & $37(69.8 \%)$ & $47(60.3 \%)$ & \\
\hline \multirow[t]{2}{*}{ Simple procedure } & No & $213(73.2 \%)$ & $106(67.1 \%)$ & 0.173 & $17(32.1 \%)$ & $25(32.1 \%)$ & 0.998 \\
\hline & Yes & $78(26.8 \%)$ & $52(32.9 \%)$ & & $36(67.9 \%)$ & $53(67.9 \%)$ & \\
\hline \multirow[t]{2}{*}{ Possible reaction from friends and family } & No & $224(77.0 \%)$ & $118(74.7 \%)$ & 0.586 & $49(92.5 \%)$ & $74(94.9 \%)$ & $0.714^{* *}$ \\
\hline & Yes & $67(23.0 \%)$ & $40(25.3 \%)$ & & $4(7.5 \%)$ & $4(5.1 \%)$ & \\
\hline \multirow[t]{2}{*}{ Not being informed } & No & $212(72.9 \%)$ & $121(76.6 \%)$ & 0.389 & $41(77.4 \%)$ & $63(80.8 \%)$ & 0.636 \\
\hline & Yes & $79(27.1 \%)$ & $37(23.4 \%)$ & & $12(22.6 \%)$ & $15(19.2 \%)$ & \\
\hline
\end{tabular}

*Pearson's chi-square test; **Fisher's exact test

surgery ( $p<0.001)$ were more likely to respond positively about their interest in being body donor for personal reasons. No other significant demographic differences were found in the perceptions of BLD or elderly people.

\section{DISCUSSION}

The majority of published data emphasize that cadaver's dissection is fundamental in medical edu- cation. A high correlation exists between PMBD and its perception as "an act of altruism". However, a considerable percentage of medical students had scant knowledge of this issue, since they were not informed about organ and tissue donation during their academic training [5]. Raikos et al. [24] in their study mentioned that the majority of young participants (73.4\%) agreed with BD for educational use, while 
only $13.8 \%$ disagree, and $12.8 \%$ did not reply or they do not know. In the current study, the most common reason for $\mathrm{BD}$ was the contribution in research, in both study groups, while the most common reason for hesitating about BD was the lack of information following by personal reasons. Blood donors were more likely to be interested in $\mathrm{BD}$ for contribution in research and personal reasons, while, comparing to the elderly, were less likely to have hesitation in being body donor for religious reasons, personal reasons or not being appropriate for it and more likely to have hesitation in being body donor for not being informed. Blood donors who declared their interest in being body donor for contribution in research were significantly older. The proportion of blood donors who declared that blood and body donation are the same was significantly higher in more educated people.

Regarding the relation between $\mathrm{BD}$ and religion, many religions show support for BD. The Hindu, Buddhist, Muslim and Christian religions all support the idea of $\mathrm{BD}$ and/or organ donation for the betterment of the world. The support of these religions is critical in many parts of the world, as many people actively practice these religions [8-10]. In the current study, blood donors not being Christian Orthodox were more likely to respond "Personal/Family reasons" and "Simple procedure" for the explanation why blood and BD are not the same as compared to the Christian Orthodox people. PMBD is not regarded as an act contrary to religious faith [5], as almost all religions globally support and encourage donation [1, 19]. Atheists and agnostics expressed a 6-fold greater approval of PMBD than Catholics [5]. This propensity shows that there are strong motivations probably linked to the awareness of the great ethical value of BD and to a widespread sentiment of civic altruism and human solidarity.

Concerning PMBD, there is a lack of specific legislation concerning the ownership of cadavers, the terms and conditions of donors' informed consent, and bodies' preservation in many countries [6]. Despite the lack of specific legislation regarding PMBD, many centres for the collection of $\mathrm{BD}$ have been established and important programmes for BD have been initiated [23]. PMBD for scientific purposes is rare in several countries, like Italy, probably due to the fact that donating the body for scientific purposes is less useful than organ donation. In the current study elderly people hesitating in being body donor for personal reasons were significantly older. In blood donors group, those who responded that blood and BD are the same were significantly younger, while in the elderly group significantly older. The proportion of blood donors who declared that blood and BD are the same was significantly higher in more educated people.

In the current study, the most common reason for hesitating about BD was the lack of information following by personal reasons in the blood donor group and personal reasons in the elderly group. The idea that one's body can be dissected may create psychological obstacles, which can only be overcome by emphasizing the importance of BD and its scientific and medical utility. Physicians and students can play a pivotal role in promoting PMBD and also may act as a good vehicle of information for patients and relatives. Although, in Ciliberti et al. [5] study, the vast majority of respondents did not consider PMBD as an insult to the human body, the authors underlined that those who did were about $80 \%$ less likely to be in favour of PMBD. Kharkar and Dase [12] pointed out that students concern that their bodies might not be handled correctly prevents BD. The ceremony with which some research institutes express their gratitude for the gift of body donors plays an important role and raises students' awareness of the need to treat donors' bodies respectfully $[2,11,12]$. Fear that death has not been adequately verified has been declared that may affect the willingness to BD. An important issue related to PMBD concerns the relationship with the family. Ciliberti et al. [5] data indicate that a high percentage of students associate PMBD with discomfort for their families. They also highlight the need for well-organised and informative BD programmes. Orientating the public towards this practice is of high moral and medical value. Media and other social bodies could take an important role in promoting this generous act, globally [25].

The questionnaire used in this pilot study will require further studies in order to allow its validation.

\section{CONCLUSIONS}

Postmortem body donation is an important source of cadavers and provides an opportunity to carry out research or educational activities in medicine and surgery. Concerning BD perception among blood donors and the elderly, the most common reason for $B D$ in both study groups was the contribution in research, while the commonest reason for hesitation in being body donor was the lack of information following by personal reasons. The blood donors were more likely to be interested in being BD for contribution in research and personal reasons. Additionally, blood donors compare to the elderly were less likely to hesitate about BD 
for religious and personal reasons and more likely to hesitate about BD for not being informed. Blood donors who declared their interest in being body donors for contribution in research were significantly older. Elderly people who hesitated about BD for personal reasons were significantly older. In the BLD group, those who responded that blood and $\mathrm{BD}$ are the same were significantly younger, while in the elderly group - significantly older. The proportion of blood donors who declared that blood and BD are the same was significantly higher in more educated people. Blood donors with family history or with previous surgery were more likely to respond positively about their interest in being body donor for personal reasons. A need for well-organised and informative $\mathrm{BD}$ programmes is evident. Orientating the public towards this practice is of high moral and medical value, since with this important promotion the altruistic act of BD will expand globally.

\section{REFERENCES}

1. Abbasi Asl J, Nikzad H, Taherian A, et al. Cultural acceptability and personal willingness of Iranian students toward cadaveric donation. Anat Sci Educ. 2017; 10(2): 120-126, doi: 10.1002/ase.1634, indexed in Pubmed: 27517382.

2. Anyanwu EG, Obikili EN, Agu AU. The dissection room experience: A factor in the choice of organ and whole body donation: a Nigerian survey. Anat Sci Educ. 2014; 7(1): 56-63, doi: 10.1002/ase.1370, indexed in Pubmed: 23650046.

3. Biasutto $\mathrm{SN}$, Sharma N, Weiglein $\mathrm{AH}$, et al. Human bodies to teach anatomy: Importance and procurement - Experience with cadaver donation. Rev Arg de Anat Clin. 2014; 6: 72-86.

4. Biasutto SN, Sharma NA, McBride J, et al. Part II - Human bodies to teach anatomy: Importance and procurement Experience with cadaver donation. Rev Arg de Anat Clin. 2014; 6: 162-175.

5. Ciliberti R, Gulino M, Gazzaniga V, et al. A Survey on the Knowledge and Attitudes of Italian Medical Students toward Body Donation: Ethical and Scientific Considerations. J Clin Med. 2018; 7(7): 168, doi: 10.3390/jcm7070168, indexed in Pubmed: 29987216.

6. Ciliberti R, Martini M, Bonsignore A, et al. Break with tradition: donating cadavers for scientific purposes and reducing the use of sentient beings. Ann Ist Super Sanita. 2016; 52(2): 261-268, doi: 10.4415/ANN_16_02_19, indexed in Pubmed: 27364402.

7. Dluzen DE, Brammer CM, Bernard JC, et al. Survey of cadaveric donors to a body donation program: 1978-1993. Clin Anat. 1996; 9(3): 183-192, doi: 10.1002/(SICI)10982353(1996)9:3<183::AID-CA10>3.0.CO;2-N, indexed in Pubmed: 8740481.

8. Dyer GS, Thorndike ME. Quidne mortui vivos docent? The evolving purpose of human dissection in medical education. Acad Med. 2000; 75(10): 969-979, indexed in Pubmed: 11031139.

9. Garment A, Lederer S, Rogers N, et al. Let the dead teach the living: the rise of body bequeathal in 20th-century America. Acad Med. 2007; 82(10): 1000-1005, doi: 10.1097/ ACM.0b013e318149e986, indexed in Pubmed: 17895666.
10. Jones DG, Whitaker MI. Anatomy's use of unclaimed bodies: reasons against continued dependence on an ethically dubious practice. Clin Anat. 2012; 25(2): 246-254, doi: 10.1002/ ca.21223, indexed in Pubmed: 21800367.

11. Jones TW, Lachman N, Pawlina W. Honoring our donors: a survey of memorial ceremonies in United States anatomy programs. Anat Sci Educ. 2014; 7(3): 219-223, doi: 10.1002/ase.1413, indexed in Pubmed: 24753299.

12. Kharkar A, Dase R. Whole body donation after death: A survey of awareness, perception and attitude in engineering students of jawaharlal nehru engineering college Aurangabad, (MS), India. IJCMAAS. 2016; 11: 42-46.

13. Korf HW, Wicht $H$, Snipes RL, et al. The dissection course necessary and indispensable for teaching anatomy to medical students. Ann Anat. 2008; 190(1): 16-22, doi: 10.1016/j. aanat.2007.10.001, indexed in Pubmed: 18342138.

14. Lagwinski M, Bernard JC, Keyser ML, et al. Survey of cadaveric donor application files: 1978-1993. Clin Anat. 1998; 11(4): 253-262, doi: 10.1002/(SICI)10982353(1998)11:4<253::AID-CA6>3.0.CO;2-S, indexed in Pubmed: 9652541.

15. Licata M, Monza F. Ethical issues in paleopathological and anthropological research experiences. Acta Biomed. 2017; 88(3): 315-318, doi: 10.23750/abm.v88i3.5653, indexed in Pubmed: 29083337.

16. Marks SC. The role of three-dimensional information in health care and medical education: the implications for anatomy and dissection. Clin Anat. 2000; 13(6): 448-452, doi: 10.1002/1098-2353(2000)13:6<448::AIDCA10>3.0.CO;2-U, indexed in Pubmed: 11111898.

17. McHanwell S, Brenner $E$, et al. The legal and ethical framework governing Body Donation in ope-A review of current practice and recommendations for good practice. Eur J Anat. 2008; 12(1): 1-24.

18. Older J. Anatomy: a must for teaching the next generation. Surgeon. 2004; 2(2): 79-90, indexed in Pubmed: 15568432.

19. Oliver M, Woywodt A, Ahmed A, et al. Organ donation, transplantation and religion. Nephrol Dial Transplant. 2011; 26(2): 437-444, doi: 10.1093/ndt/gfq628, indexed in Pubmed: 20961891.

20. Papa V, Vaccarezza M. Teaching anatomy in the XXI century: new aspects and pitfalls. Scientific World J. 2013; 2013: 310348, doi: 10.1155/2013/310348, indexed in Pubmed: 24367240.

21. Pawlina W, Hammer R, Strauss J, et al. The hand that gives the rose. Mayo Clinic Proceedings. 2011; 86(2): 139-144, doi: 10.4065/mcp.2010.0625.

22. Pawlina W, Lachman N. Dissection in learning and teaching gross anatomy: rebuttal to McLachlan. Anat Rec B New Anat. 2004; 281(1): 9-11, doi: 10.1002/ar.b.20038, indexed in Pubmed: 15558788.

23. Porzionato $A$, Polese $L$, Lezoche $E$, et al. On the suitability of Thiel cadavers for natural orifice transluminal endoscopic surgery (NOTES): surgical training, feasibility studies, and anatomical education. Surg Endosc. 2015; 29(3): 737-746, doi: 10.1007/s00464-014-3734-0, indexed in Pubmed: 25060684.

24. Raikos A, Paraskevas GK, Tzika M, et al. Human body exhibitions: public opinion of young individuals and contemporary bioethics. Surg Radiol Anat. 2012; 34(5): 433-440, doi: 10.1007/s00276-011-0925-4, indexed in Pubmed: 22209912.

25. Srdić Galić B, Drvendžija Z, Štrkalj G. Attitudes of medical and allied medical students from Serbia toward whole body donation. Bioscience J. 2016; 32: 1388-1402, doi: 10.14393/bj-v32n1a2016-34414. 